Check for updates

Cite this: RSC Adv., 2018, 8, 22062

\title{
A galactose-mediated targeting nanoprobe for intracellular hydroxyl radical imaging to predict drug-induced liver injury $\dagger$
}

\begin{abstract}
Bailing Ma, Mi Lu, Bo-Yang Yu (D) * and Jiangwei Tian (D) *
Drug-induced liver injury (DILI) is a serious concern in modern medicine due to its unpredictability. Currently, biochemical serum markers are being used in DILI detection. However, these biomarkerbased methods lack sensitivity and specificity. A high intracellular level of hydroxyl radicals $(\cdot \mathrm{OH})$ has been regarded as an early indicator of DILI. Therefore, we proposed an ${ }^{\circ} \mathrm{OH}$-responsive and hepatocyte-targeted nanoprobe via conjugation of carboxyfluorescein-labeled DNA and pegylated galactose on the surface of gold nanoparticles. The nanoprobe could bind to a hepatocyte-specific asialoglycoprotein receptor through galactose, and it could be internalized into liver cells. In the presence of high levels of ${ }^{\circ} \mathrm{OH}$ in DILI, the DNA could be cleaved to release carboxyfluorescein, leading to remarkable fluorescence enhancement for ${ }^{\circ} \mathrm{OH}$ detection. Confocal fluorescence imaging demonstrated that the nanoprobe could be successfully applied in monitoring high ${ }^{\circ} \mathrm{OH}$ levels resulting from acetaminophen or triptolide-induced liver injury, which may provide a simple but powerful protocol for the prediction of DILI.
\end{abstract}

Received 14th February 2018

Accepted 4th June 2018

DOI: $10.1039 / \mathrm{c} 8 \mathrm{ra} 01424 \mathrm{~h}$

rsc.li/rsc-advances direct or indirect oxidation of phase I metabolizing enzymes in the early DILI process. ${ }^{12-16}$ In particular, the hydroxyl radical $\left({ }^{\circ} \mathrm{OH}\right)$ is the strongest oxidizing agent among ROS, and it can cause irreversible oxidative damage to DNA. ${ }^{\mathbf{1 7 - 2 0}}$ Therefore, the accurate detection of endogenous ${ }^{\circ} \mathrm{OH}$ during DILI may contribute insights into the mechanism of drug-induced hepatotoxicity.

To achieve this goal, an 'OH-responsive and hepatocyte-targeted nanoprobe based on Förster resonance energy transfer (FRET) was developed in this work to evaluate the drug-induced hepatotoxicity. The nanoprobe was constructed by covalent conjugation of thiolated single-stranded oligonucleotide labelled with carboxyfluorescein (HS-AGGGTTAGGG-FAM) and thiolpoly(ethylene glycol)2000-galactose (HS-PEG 2000 -Gal) on the surface of gold nanoparticles (AuNPs). Due to the high quenching efficiency, ${ }^{21}$ convenient surface modification ${ }^{22}$ and good biocompatibility ${ }^{23}$ of AuNPs, they can serve as ideal carriers and electron acceptors in the prepared nanoprobe. The close proximity of AGGGTTAGGG-FAM to AuNP results in strong inhibition of FAM fluorescence due to the FRET effect. Additionally, $\mathrm{PEG}_{2000}-\mathrm{Gal}$ is also immobilized on the surface of AuNPs to ensure stability and specific recognition toward the asialoglycoprotein receptor (ASGPR)-rich hepatocyte. ${ }^{24,25}$ After the nanoprobe is specifically internalized into the liver cells through ASGPR-mediated endocytosis, AGGGTTAGGG with TT as the recognition sequence ${ }^{26}$ can be cleaved by ${ }^{\circ} \mathrm{OH}$ during DILI to release FAM from the surface of AuNPs, leading to a distinct fluorescence enhancement at $520 \mathrm{~nm}$. By virtue of confocal fluorescence imaging, DILI can be detected and visualized in a noninvasive manner in living cells, 


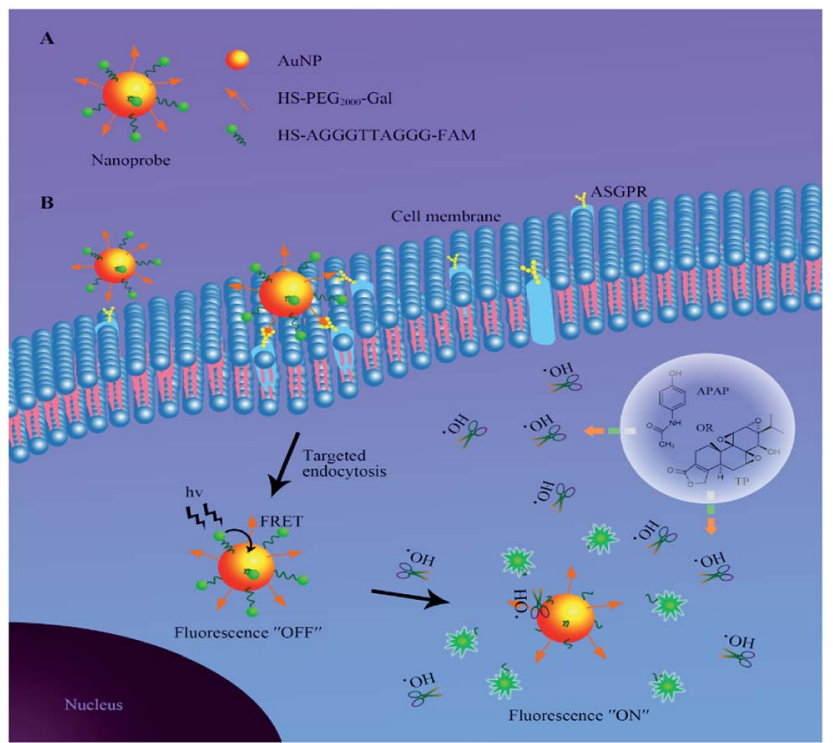

Scheme 1 A schematic illustration of $(A)$ the structure of the nanoprobe and (B) function of fluorescence activation via elevated ${ }^{\circ} \mathrm{OH}$ levels during DILI in liver cells.

which provides a new method to detect DILI at an early stage (Scheme 1).

\section{Results and discussion}

\section{Characterization of the nanoprobe}

AuNPs were synthesized using the classical citrate reduction method. ${ }^{27}$ The UV-Vis absorption spectrum of AuNPs revealed that the maximum absorption of AuNPs was at $519 \mathrm{~nm}$ (Fig. S1†). In addition, the absorption spectrum of AuNPs overlapped with the emission spectrum of FAM, which peaked at $520 \mathrm{~nm}$, and this indicated that the fluorescence of FAM could be effectively quenched by AuNPs due to the FRET effect.
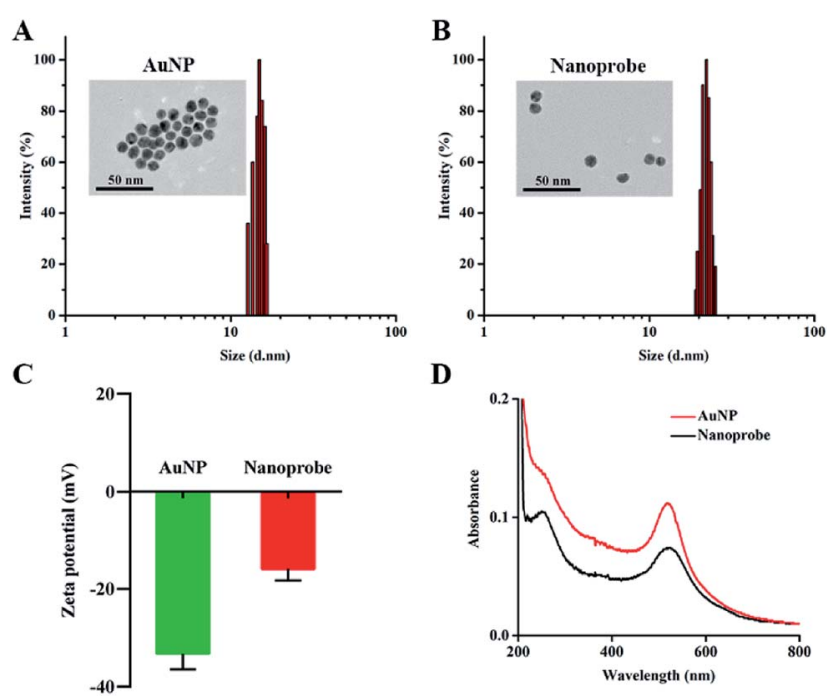

D

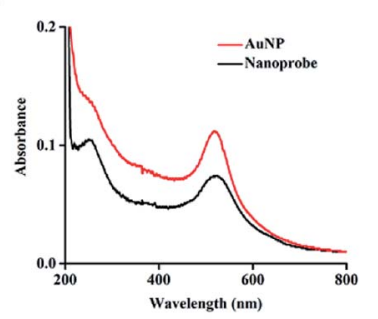

Fig. 1 (A) TEM image (inset) and size distribution of AuNPs. (B) TEM image (inset) and size distribution of the nanoprobe. (C) Zeta potentials of AuNPs and the nanoprobe. (D) Absorption spectra of AuNPs and the nanoprobe.
The transmission electron microscopy (TEM) image verified the formation of uniform and spherical AuNPs (Fig. 1A), and the average hydrodynamic diameter of AuNPs was measured to be approximately $15.6 \mathrm{~nm}$ by dynamic light scattering (DLS) (Fig. 1A). The nanoprobe was synthesized though a rapid and facile method based on the synergistic protection effect of PEG on AuNPs. ${ }^{28}$ The TEM image (Fig. 1B) exhibited that the nanoprobe was similar to AuNPs but with high dispersibility owing to successful PEG conjunction. Meanwhile, the DLS result showed that the hydrodynamic diameter of the nanoprobe increased from approximately $15.6 \mathrm{~nm}$ (Fig. 1A) to $22.0 \mathrm{~nm}$ (Fig. 1B), indicating that the surface coating of $\mathrm{PEG}_{2000}-\mathrm{Gal}$ and oligonucleotides increased the size of the nanoprobe. Furthermore, the zeta potential of AuNPs was measured to be $-34.2 \mathrm{mV}$ (Fig. 1C), which suggested high stability of AuNPs due to the presence of the negatively charged citrate ligand. The zeta potential of the nanoprobe increased to $-14.9 \mathrm{mV}$; this could be because the citrate salt on the surface of AuNPs was replaced by $\mathrm{PEG}_{2000}$-Gal and oligonucleotides via a ligand exchange reaction. The zeta potential was approximately $-15 \mathrm{mV}$, indicating that the nanoprobe was still stable in aqueous solution. ${ }^{29}$ Moreover, in contrast to the UV-Vis spectrum of AuNPs with only one absorption peak at $519 \mathrm{~nm}$, the UV-Vis spectrum of the nanoprobe exhibited an extra characteristic DNA peak at $260 \mathrm{~nm}$ (Fig. 1D), confirming the successful conjugation of DNA sequences on the AuNP surface. The number of DNA molecules modified on the AuNPs was calculated based on the mercaptoethanol reduction method. ${ }^{30}$ It was confirmed that each AuNP carried approximately $159 \pm 2$ FAM-DNA (Fig. S2 $†$ ). Taken together, these results indicated that the nanoprobe was successfully assembled.

\section{Response of the nanoprobe toward ${ }^{\circ} \mathrm{OH}$}

After characterization of the nanoprobe, we tested its fluorescence response toward ${ }^{\circ} \mathrm{OH}$ generated by a Fenton reaction $\left(\mathrm{Fe}^{2+}\right.$ $\left.+\mathrm{H}_{2} \mathrm{O}_{2}=\mathrm{Fe}^{3+}+\mathrm{OH}^{-}+{ }^{\circ} \mathrm{OH}\right)$ using different concentrations of $\mathrm{Fe}^{2+}$ and excessive $\mathrm{H}_{2} \mathrm{O}_{2}\left(1: 6 \mathrm{~mol}\right.$ per mol) ${ }^{31}$ Therefore, the concentration of $\mathrm{Fe}^{2+}$ in the Fenton reaction served as the concentration of ${ }^{\circ} \mathrm{OH}$ in the following experiments. There was almost no background fluorescence in the absence of ${ }^{\circ} \mathrm{OH}$ (Fig. 2A and B) because of the high quenching efficiency of AuNPs with respect to FAM. After the addition of $1 \mu \mathrm{M}{ }^{\circ} \mathrm{OH}$, a significant fluorescence enhancement of the nanoprobe was observed owing to the elimination of the FRET effect, which was induced by the cleavage of DNA. Kinetic studies showed that the nanoprobe responded to ${ }^{\circ} \mathrm{OH}$ within $15 \mathrm{~min}$ (Fig. S3†). The relatively long response time could be ascribed to the slow Fenton reaction with a rate constant of $40-80 \mathrm{~mol}^{-1} \mathrm{~L} \mathrm{~s}^{-1}$. $^{32}$ Furthermore, when dimethyl sulfoxide (DMSO) as a typical ${ }^{\circ} \mathrm{OH}$ scavenger ${ }^{33}$ was added into the reaction mixture of $\mathrm{Fe}^{2+}$ and $\mathrm{H}_{2} \mathrm{O}_{2}$, the fluorescence of the nanoprobe was significantly suppressed, confirming that the emission of the nanoprobe was due to the $\mathrm{OH}$-induced breakage of DNA chains. The fluorescence intensity of the nanoprobe increased gradually along with the concentration of ${ }^{\circ} \mathrm{OH}$ from 0 to $1 \mu \mathrm{M}$ (Fig. 2C). A good linear correlation between the fluorescence intensity and 

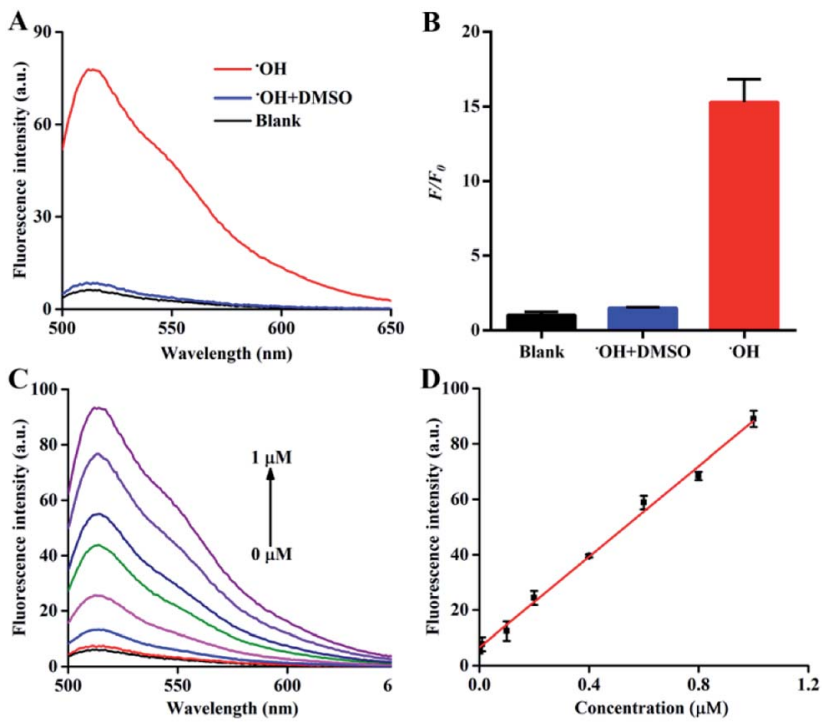

Fig. 2 (A) Fluorescence spectral responses and (B) relative fluorescence intensity $\left(F / F_{0}\right)$ at $520 \mathrm{~nm}$ of the nanoprobe with respect to ${ }^{\circ} \mathrm{OH}$ in the absence or presence of DMSO. (C) Fluorescence spectra of $1 \mathrm{nM}$ nanoprobe after addition of $0,0.01,0.1,0.2,0.4,0.6,0.8$ and $1 \mu \mathrm{M} \cdot{ }^{\circ} \mathrm{OH}$. (D) Linear correlation between ${ }^{\circ} \mathrm{OH}$ concentration and fluorescence intensity at $520 \mathrm{~nm}$. Data are means \pm SD $(n=3)$.

concentration of ${ }^{\circ} \mathrm{OH}$ was obtained with $F=6.52179+71.76379$ $\left[{ }^{\circ} \mathrm{OH}\right]\left(R^{2}=0.9963\right)$ (Fig. 2D). The selectivity of the nanoprobe towards ${ }^{\circ} \mathrm{OH}$ was examined by monitoring the fluorescence changes in the presence of various ROS, reactive nitrogen species (RNS) and iron. Significant fluorescence enhancement was observed for ${ }^{\circ} \mathrm{OH}$, whereas other interferences could not induce the fluorescence change, verifying the high selectivity of the nanoprobe towards ${ }^{\circ} \mathrm{OH}$ (Fig. S4 $\dagger$ ). The fluorescent stability of the nanoprobe was also investigated in phosphate buffered saline (PBS) and Dulbecco's modified Eagle's medium (DMEM) with $10 \%$ fetal bovine serum (FBS). The fluorescence of the nanoprobe showed negligible changes in these two media from 1 to 7 days (Fig. S5 $\dagger$ ). The results revealed the sensitivity, specificity and stability of the nanoprobe for ${ }^{\circ} \mathrm{OH}$ detection.

\section{Biocompatibility of the nanoprobe}

To evaluate the biocompatibility of the nanoprobe in living cells, an MTT (3-(4,5-dimethylthiazol-2-yl)-2,5diphenyltetrazolium bromide) assay was carried out in the human normal liver cell line L-02. The absorbance of the produced formazan at $490 \mathrm{~nm}$ depends on the cell viability. The MTT assay showed that AuNPs and the nanoprobe were almost noncytotoxic to living cells at concentrations of up to $2.5 \mathrm{nM}$ (Fig. 3A) after $24 \mathrm{~h}$ incubation (Fig. 3B), which revealed that the nanoprobe exhibited good biocompatibility in living cells.

\section{Cellular uptake of the nanoprobe}

After incubation with liver cells, it was found that the intracellular amount of the nanoprobe was much more than that of the nanoprobe without Gal (Fig. 4). The galactose residue of $\mathrm{PEG}_{2000}$-Gal exposed on the surface of the nanoprobe could promote cellular uptake of the nanoprobe into hepatocytes by
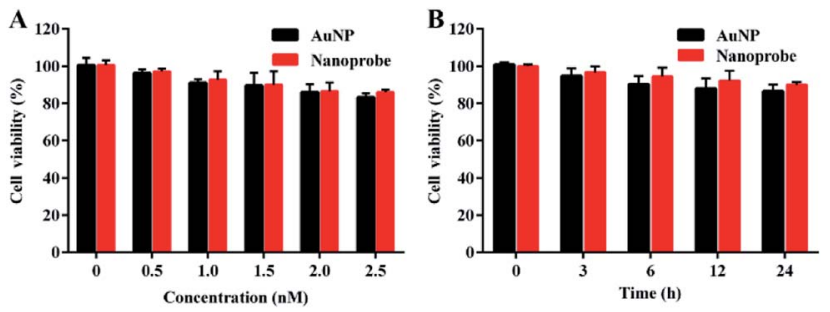

Fig. 3 (A) MTT assay of L-02 cells incubated with varying concentrations of AuNPs and the nanoprobe for $24 \mathrm{~h}$. (B) MTT assay of L-02 cells treated with $1 \mathrm{nM}$ AuNPs and the nanoprobe at different times. Data are means $\pm \mathrm{SD}(n=3)$.

an ASGPR-mediated endocytosis pathway. The increased size of $100 \mathrm{~nm}$ of the intracellular nanoprobes was due to the trapping and aggregation of multiple nanoprobes in the lysosomal compartments. The result demonstrated that the nanoprobe with Gal modification could effectively target the liver cells.

\section{Imaging of ${ }^{\circ} \mathrm{OH}$ in APAP-induced liver injury and the remediation effect of NAC or QUE}

The nanoprobe was used to investigate the fluctuation in ${ }^{\circ} \mathrm{OH}$ levels in liver cells under different pathological conditions by confocal fluorescence imaging. Acetaminophen (APAP), a widely used analgesic and antipyretic drug, is mainly employed to treat pain and fever. ${ }^{34}$ An overdose of APAP can result in the excessive production of ROS and RNS, which is a major cause of liver injury through enzymatic biotransformation ${ }^{35,36}$ The cell viability of L-02 cells decreased to $85 \%$ with a concentration of APAP of $8 \mathrm{mM}$ (Fig. S6A $\dagger$ ), and the intracellular ROS level clearly increased (Fig. S6B $\dagger$ ), revealing that the cells were slightly injured by ROS. The L-02 cells were treated with APAP and
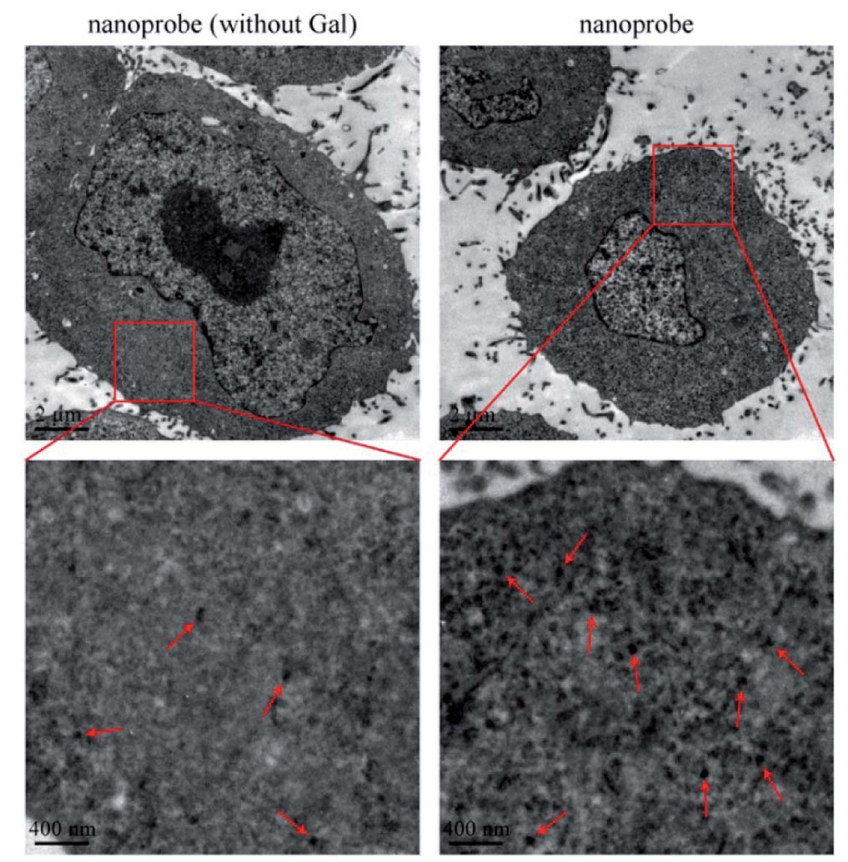

Fig. 4 TEM images of cellular uptake of nanoprobe (without Gal) and nanoprobe. The pictures displayed below are the enlarged views of the red frames. 
incubated with the nanoprobe to perform confocal fluorescence imaging. The intracellular fluorescence intensity increased gradually with the increasing concentration of APAP (Fig. 5) and incubation time of the nanoprobe (Fig. S7†), which indicated $\cdot \mathrm{OH}$ production in the process of APAP-induced liver cell injury. Conversely, no difference in the activity of ALT or AST as the classical serum biomarker was observed after the cells were treated with different concentrations of APAP for $4 \mathrm{~h}(\dagger)$, which confirmed that ${ }^{\circ} \mathrm{OH}$ imaging using the nanoprobe was more sensitive than the conventional methods for DILI detection.

Subsequently, the nanoprobe was used to examine the protective effect of drugs on APAP-induced liver cell injury. $\mathrm{N}$ acetylcysteine (NAC) and quercetin (QUE) as active ingredients for protecting against liver injury ${ }^{37-39}$ were added before the APAP treatment. NAC acts as an antidote to APAP-induced liver injury though upregulation of the intracellular GSH and elimination of ROS. ${ }^{37,38}$ QUE is an effective antioxidant, which can directly remove various free radicals and inhibit oxidative stress. ${ }^{39}$ The MTT assay showed that NAC (Fig. S8A $\dagger$ ) and QUE (Fig. S9A $\dagger$ ) were nontoxic to L-02 cells. The $8 \mathrm{mM}$ APAP-induced intracellular ROS production could be significantly suppressed by $2 \mathrm{mM}$ NAC (Fig. S8B $\dagger$ ) and $20 \mu \mathrm{M}$ QUE (Fig. S9B $\dagger$ ). Confocal fluorescence imaging revealed that pre-treatments with NAC (Fig. S10†) and QUE (Fig. S11†) could remarkably reduce the fluorescence of the nanoprobe compared to that of single APAP administration. These results verified that the nanoprobe can be employed to visualize the protective effects of NAC and QUE on APAP-induced liver cell injury.

\section{Imaging of ${ }^{\circ} \mathrm{OH}$ in TP-induced liver injury}

Triptolide (TP) is a diterpenoid triepoxide with a variety of biological activities. ${ }^{40}$ However, the potential hepatotoxicity of TP is associated with the intracellular accumulation of ROS, which limits its clinical application. ${ }^{41}$ To investigate the hepatotoxicity of TP, L-02 cells were incubated with TP for performing MTT and ROS assays. There was only slight reduction in the cell viability of L-02 cells at a concentration of up to $120 \mathrm{nM}$ (Fig. S12A $\dagger$ ) and an incubation time of $12 \mathrm{~h}$ (Fig. S13A $\dagger$ ). On the contrary, the level of intracellular ROS clearly increased at a concentration of $120 \mathrm{nM}$ of TP (Fig. S12B $\dagger$ ) and an incubation time of $12 \mathrm{~h}$ (Fig. S13B $\dagger$ ), suggesting that the intracellular high-expression of ROS could be used as a more sensitive indicator to reflect the TP-induced liver cell injury. Therefore, the L- 02 cells were treated with TP and then incubated with the nanoprobe to implement confocal fluorescence imaging. The

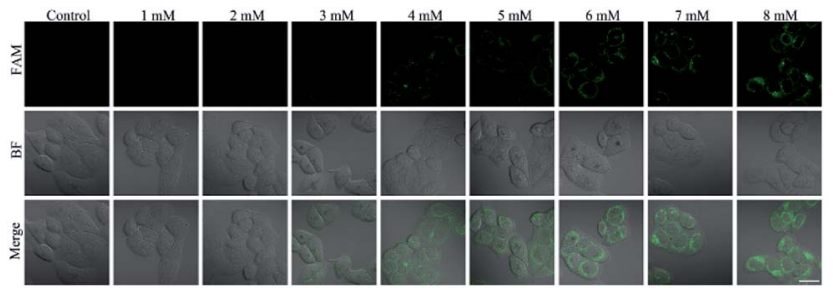

Fig. 5 Confocal fluorescence, bright field (BF) and merged images of $\mathrm{L}-02$ cells pre-treated with various concentrations of APAP for $4 \mathrm{~h}$ and then incubated with $1 \mathrm{nM}$ nanoprobe for $2 \mathrm{~h}$. Scale bar: $20 \mu \mathrm{m}$.

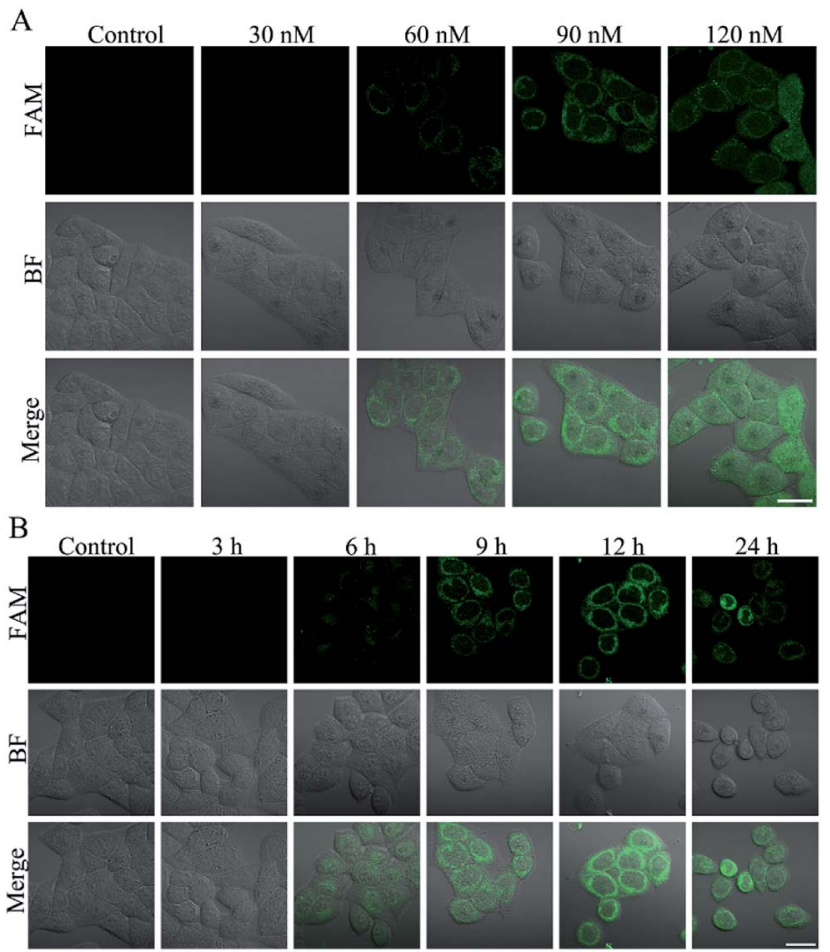

Fig. 6 (A) Confocal fluorescence, BF and merged images of L-02 cells treated with various concentrations of TP for $12 \mathrm{~h}$ and then incubated with $1 \mathrm{nM}$ nanoprobe for $2 \mathrm{~h}$. (B) Confocal fluorescence, BF and merged images of L-02 cells treated with $120 \mathrm{nM}$ TP at different times and then incubated with $1 \mathrm{nM}$ nanoprobe for $2 \mathrm{~h}$. Scale bar: $20 \mu \mathrm{m}$.

green fluorescence of the nanoprobe in the L-02 cells increased gradually along with the increasing concentration (Fig. 6A) and time (Fig. 6B), and the fluorescence was distinct when the TP concentration was $60 \mathrm{nM}$ and the incubation time was $6 \mathrm{~h}$, indicating that the intracellular ${ }^{\circ} \mathrm{OH}$ generation during $\mathrm{TP}$ treatment could be detected by the nanoprobe at a low dosage and early time. We also determined the activity changes of ALT and AST in L-02 cells treated with various concentrations of TP for $12 \mathrm{~h}$. No significant difference was found in the activities of ALT (Fig. S12C $\dagger$ ) and AST (Fig. S12D $\dagger$ ). L-02 cells were incubated with $120 \mathrm{nM}$ TP for different times. After $24 \mathrm{~h}$ of TP administration, a remarkable change in the activities of ALT (Fig. S13C $\dagger$ ) and AST (Fig. S13D $\dagger$ ) could be observed. It is noteworthy that the positive time of $6 \mathrm{~h}$ using nanoprobe imaging was superior to that of $24 \mathrm{~h}$ for ALT- and AST-based conventional detection methods, demonstrating the generality and advantage of the nanoprobe for the early detection of DILI.

\section{Experimental section}

\section{Materials and reagents}

Chloroauric acid $\left(\mathrm{HAuCl}_{4} \cdot 4 \mathrm{H}_{2} \mathrm{O}, 99.99 \%\right)$, sodium citrate $\left(\mathrm{Na}_{3} \mathrm{C}_{6} \mathrm{H}_{5} \mathrm{O}_{7}\right)$, sodium chloride $(\mathrm{NaCl})$, tween20, hydrogen peroxide $\left(\mathrm{H}_{2} \mathrm{O}_{2}, 30 \%\right)$, sodium hypochlorite solution and ferrous sulfate $\left(\mathrm{FeSO}_{4} \cdot 7 \mathrm{H}_{2} \mathrm{O}\right)$ were purchased from Sinopharm Chemical Reagent Co. Ltd. (Shanghai, China). Acetaminophen (APAP), $N$-acetylcysteine (NAC) and triptolide (TP) were purchased from Aladdin Co. Ltd. (Shanghai, China). 
Ethylenediaminetetraacetic acid (EDTA), quercetin (QUE) and $2^{\prime}, 7^{\prime}$-dichlorodihydrofluorescein diacetate (DCFH-DA) were purchased from Sigma-Aldrich (St. Louis, MO, USA). 3-(4,5dimethylthiazol-2-yl)-2,5-diphenyltetra zolium bromide (MTT) was purchased from KeyGen Biotech. Co. Ltd. (Nanjing, China). Quantitative detection kits for alanine aminotransferase (ALT) and aspartate aminotransferase (AST) were obtained from Nanjing Jiancheng Bioengineering Institute (Nanjing, China). FAM-modified single-stranded oligonucleotide (5'-FAM- $\left(\mathrm{CH}_{2}\right)_{6}{ }^{-}$ AGGGTTAGGG- $\left(\mathrm{CH}_{2}\right)_{3}$-SH-3') was synthesized and purified by Sangon Biotech Co. Ltd. (Shanghai, China). Thiol-poly(ethylene glycol)2000-galactose (HS-PEG 2000 -Gal) and thiolmonomethoxypolyethylene glycol 2000 ( $\left.\mathrm{mPEG}_{2000}-\mathrm{SH}\right)$ were synthesized and purified by Hunan Huateng Pharmaceutical Co. Ltd. (Hunan, China). All chemicals were of analytical grade and used without further purification. Ultrapure water was prepared using the Millipore Simplicity System (Millipore, Bedford, USA) with a resistivity of $18.2 \mathrm{M} \Omega$.

\section{Apparatus}

Absorption spectra were recorded on an UV-2550 UV-Vis spectrophotometer (Shimadzu Company, Japan). Fluorescence spectra were measured on a Carry Eclipse Fluorescence spectrophotometer (Agilent, USA). The hydrodynamic diameters of the nanoparticles were measured by dynamic light scattering (DLS) at $25{ }^{\circ} \mathrm{C}$ using 90 Plus/BI-MAS equipment (Brookhaven, USA). The morphology of the nanoparticle was characterized with a Hitachi HT7700 transmission electron microscope (TEM) operating at $200 \mathrm{kV}$. Zeta potential measurements were obtained at $25{ }^{\circ} \mathrm{C}$ on a Zetasizer (Nano-Z, Malvern, UK). The MTT assay was measured by a microplate reader (Biotek, USA). Confocal fluorescence imaging of cells was performed on a confocal laser scanning microscope (CLSM, LSM800, Zeiss, Germany).

\section{Preparation of AuNPs and the nanoprobe}

AuNPs were prepared by the citrate reduction method. ${ }^{42}$ In brief, $10 \mathrm{~mL}$ trisodium citrate $(0.25 \%)$ was rapidly added into a boiling $100 \mathrm{~mL} \mathrm{HAuCl}_{4}$ solution $(0.01 \%)$ with strong stirring. The solution was maintained with continuous stirring for $30 \mathrm{~min}$. Afterwards, the solution was allowed to cool to room temperature and stored at $4{ }^{\circ} \mathrm{C}$. The AuNP concentration was measured by UV-Vis spectroscopy using molar extinction coefficients at the wavelength of maximum absorption, as reported previously. ${ }^{43}$

The nanoprobe was prepared by a rapid and facile method. ${ }^{28}$ Ten $\mu \mathrm{L}$ of $1 \mathrm{wt} \%$ tween 20 and $20 \mu \mathrm{L}$ of $10 \mu \mathrm{M}$ Gal-PEG ${ }_{2000}-\mathrm{SH}$ were added into $1 \mathrm{~mL}$ of $2 \mathrm{nM}$ AuNP solution to obtain final concentrations of $0.01 \%$ Tween 20 and 200 nM Gal- $\mathrm{PEG}_{2000}-\mathrm{SH}$, respectively. After mixing, $6 \mu \mathrm{L}$ of $100 \mu \mathrm{M}$ thiolated DNA was added to the mixture and then, $2 \mathrm{M} \mathrm{NaCl}$ solution was added to obtain a final concentration of $0.8 \mathrm{M}$. After aging for $60 \mathrm{~min}$ at room temperature, unbound reagents were removed by centrifugation $\left(12000 \mathrm{rpm}, 20 \mathrm{~min}, 4{ }^{\circ} \mathrm{C}\right)$. The precipitate was centrifuged and washed three times with PBS. The $\mathrm{mPEG}_{2000^{-}}$
SH and DNA-modified AuNPs were prepared using a similar method.

\section{Quantitation of DNA chains loaded on the AuNPs}

DNA chains loaded on AuNPs were quantitated according to a published protocol. ${ }^{30}$ Briefly, mercaptoethanol was added (final concentration $20 \mathrm{mM}$ ) into $1 \mathrm{nM}$ nanoprobe solution; the mixture was incubated with stirring for $12 \mathrm{~h}$ at room temperature. The released DNA chains were collected via centrifugation, and the fluorescence intensity of FAM-DNA was measured with a fluorescence spectrometer. The fluorescence was converted to molar concentration of DNA chains via calculations from a standard linear calibration curve prepared with known concentrations of FAM-DNA with identical buffer $\mathrm{pH}$, ionic strength and DNA concentrations.

\section{Fluorescence measurements}

In the fluorescence assay, ${ }^{\circ} \mathrm{OH}$ was generated through the Fenton reaction $\left(\mathrm{Fe}^{2+}+\mathrm{H}_{2} \mathrm{O}_{2}=\mathrm{Fe}^{3+}+\mathrm{OH}^{-}+{ }^{\circ} \mathrm{OH}\right)$ by different amounts of $\mathrm{Fe}^{2+}$ and excess $\mathrm{H}_{2} \mathrm{O}_{2}(1: 6 \mathrm{~mol}$ per mol). Therefore, in the following experiments, the concentration of $\mathrm{Fe}^{2+}$ in the Fenton reaction served as the concentration of ${ }^{\circ} \mathrm{OH}$. A certain concentration of ${ }^{\circ} \mathrm{OH}\left(\mathrm{Fe}^{2+}\right.$ with concentrations of $0,0.01,0.1$, $0.2,0.4,0.6,0.8$, and $1 \mu \mathrm{M})$ generated through the Fenton reaction by different amounts of $\mathrm{Fe}^{2+}$ and $\mathrm{H}_{2} \mathrm{O}_{2}$ was added to $1 \mathrm{nM}$ nanoprobe solution. After incubation at $37^{\circ} \mathrm{C}$ for $15 \mathrm{~min}$, the fluorescence intensity of the mixture was excited at $488 \mathrm{~nm}$ and measured at $520 \mathrm{~nm}$. To investigate the specificity of the nanoprobe for ${ }^{\circ} \mathrm{OH}, 0.1 \%$ DMSO was added to the $1 \mathrm{nM}$ nanoprobe solution before the addition of $1 \mu \mathrm{M} \mathrm{Fe}^{2+}$ and $6 \mu \mathrm{M}$ $\mathrm{H}_{2} \mathrm{O}_{2}$. After incubation at $37{ }^{\circ} \mathrm{C}$ for $15 \mathrm{~min}$, the fluorescence intensity of the mixture was excited at $488 \mathrm{~nm}$ and measured at $520 \mathrm{~nm}$.

\section{Kinetics of the nanoprobe}

Fenton reagents were added to $1 \mathrm{nM}$ nanoprobe solution. The fluorescence intensity of the mixture was scanned from 0 to $30 \mathrm{~min}$ in the absence and presence of $1 \mu \mathrm{M}{ }^{\circ} \mathrm{OH}\left(1 \mu \mathrm{M} \mathrm{Fe}^{2+}\right.$ and $6 \mu \mathrm{M} \mathrm{H}_{2} \mathrm{O}_{2}$ ). The fluorescence intensity of the mixture was excited at $488 \mathrm{~nm}$ and measured at $520 \mathrm{~nm}$.

\section{Selectivity experiment}

Fluorescence responses of $1 \mathrm{nM}$ nanoprobe in PBS buffer $(0.01 \mathrm{M}, \mathrm{pH}=7.4)$ toward different ROS and RNS including ${ }^{\circ} \mathrm{OH}$ $(1 \mu \mathrm{M})$, singlet oxygen $\left({ }^{1} \mathrm{O}_{2}, 1 \mu \mathrm{M}\right), \mathrm{H}_{2} \mathrm{O}_{2}(1 \mu \mathrm{M})$, superoxide anion radical $\left(\mathrm{O}^{2 \cdot-}, 1 \mu \mathrm{M}\right)$, tert-butyl hydroperoxide (TBHP, 1 $\mu \mathrm{M})$, tert-butyl peroxyl radical $\left(\mathrm{O} t \mathrm{Bu}^{-}, 1 \mu \mathrm{M}\right)$, peroxynitrite anion $\left(\mathrm{ONOO}^{-}, 1 \mu \mathrm{M}\right)$, hypochlorite anion $\left(\mathrm{ClO}^{-}, 1 \mu \mathrm{M}\right)$ and $\mathrm{Fe}^{2+}(1 \mathrm{mM})$ were tested. The fluorescence intensity of mixture was detected after incubation at $37{ }^{\circ} \mathrm{C}$ for $15 \mathrm{~min} .{ }^{1} \mathrm{O}_{2}$ was formed by the addition of $\mathrm{NaClO}$ to $\mathrm{H}_{2} \mathrm{O}_{2}$ (1:1 mol per mol), and $\mathrm{O}^{2 \cdot-}$ was obtained by $1 \mu \mathrm{M} \mathrm{KO}_{2}$ in DMSO. $\mathrm{O} t \mathrm{Bu}^{-}$was obtained via the addition of TBHP to $\mathrm{H}_{2} \mathrm{O}_{2}(1: 1 \mathrm{~mol}$ per mol). $\mathrm{ONOO}^{-}$was obtained by the addition of $\mathrm{NaNO}_{2}$ to $\mathrm{H}_{2} \mathrm{O}_{2}$ (1: 1 mol per mol). ${ }^{31,44}$ 


\section{Stability of the nanoprobe}

An equal volume of PBS or DMEM with $10 \%$ FBS was added into the nanoprobe $(1 \mathrm{nM})$ and then, the fluorescence intensity of the nanoprobe was measured by a fluorescence spectrometer at $0,1,2,3,4,5,6$ and 7 days.

\section{Cell culture}

Human normal liver cell line (L-02) was obtained from KeyGEN Biotech Co. Ltd. (Nanjing, China). L-02 cells were cultured in Dulbecco's modified Eagle's medium (DMEM, Gibco) supplemented with $10 \%$ fetal calf serum (FBS, sigma), penicillin (100 $\left.\mu \mathrm{g} \mathrm{mL} \mathrm{m}^{-1}\right)$, and streptomycin $\left(100 \mu \mathrm{g} \mathrm{mL} \mathrm{m}^{-1}\right)$ at $37{ }^{\circ} \mathrm{C}$ in a humidified incubator containing $5 \% \mathrm{CO}_{2}$ and $95 \%$ air. The medium was replenished every other day, and the cells were subcultured after reaching confluence.

\section{MTT assay}

The cytotoxicities of the nanoprobe and AuNPs to L-02 cells were investigated by using the MTT assay. Briefly, the L-02 cells were seeded into 96-well plates $\left(4 \times 10^{3}\right.$ cells per well $)$ in a total volume of $200 \mu \mathrm{L}$ per well and then incubated overnight. After the original medium was removed, AuNPs and the nanoprobe $(0,0.5,1,1.5,2$ or $2.5 \mathrm{nM})$ were added. The cells were incubated for $24 \mathrm{~h}$. Then, $20 \mu \mathrm{L}$ of MTT solution ( $5 \mathrm{mg} \mathrm{mL}^{-1}$ in PBS) was added for another $4 \mathrm{~h}$. After that, the MTT solution was carefully removed. Formazan crystals were solubilized by the addition of $150 \mu \mathrm{L}$ DMSO, and the absorbance at $490 \mathrm{~nm}$ was measured on an automated microtiter plate reader. Cell viability was calculated based on the absorbance at $490 \mathrm{~nm}$.

\section{Cellular uptake of the nanoprobe}

L-02 cells were seeded onto 6-well plates and incubated with $1 \mathrm{nM}$ AuNP and nanoprobe for $2 \mathrm{~h}$. Cells with internalized nanoparticles were washed with PBS, trypsinized, and centrifuged to remove excess nanoparticles. Next, the cells were fixed with $1 \mathrm{~mL}$ fresh $2.5 \%$ glutaraldehyde. After one day, the cells were washed with PBS to remove the fixatives and then, they were dehydrated in an alcohol series, embedded in epon, and sliced to a $\sim 75 \mathrm{~nm}$ thickness. TEM images of the slices were obtained with Hitachi HT7700.

\section{ROS detection}

In the experiments for ROS levels of APAP-induced liver injury, L-02 cells $\left(4 \times 10^{3}\right.$ cells per well $)$ were seeded in 96-well blank plate and exposed to APAP (1-8 mM) for $4 \mathrm{~h}$. After that, the cells were incubated with DCFH-DA $(10 \mu \mathrm{M})$ for $30 \mathrm{~min}$ at $37^{\circ} \mathrm{C}$ in the dark and then, they were washed in $100 \mu \mathrm{L}$ ice-cold PBS. Fluorescence was measured using a microplate reader (Thermo Scientific Vario Skan Flash, USA) with the excitation wavelength at $488 \mathrm{~nm}$ and the emission wavelength at $520 \mathrm{~nm}$.

In the experiment for the remediation effect of NAC or QUE, L-02 cells $\left(4 \times 10^{3}\right.$ cells per well $)$ were seeded in a 96-well blank plate and exposed to $8 \mathrm{mM}$ APAP for $4 \mathrm{~h}$ following incubation with NAC $(0.5,1,2 \mathrm{mM})$ or QUE $(5,10,20 \mu \mathrm{M})$ for $1 \mathrm{~h}$ and then, $8 \mathrm{mM}$ APAP was added for another $4 \mathrm{~h}$. After that, the fluorescence was measured with the same experimental procedures as mentioned.

In the experiment for ROS levels of TP-induced liver injury, L02 cells $\left(4 \times 10^{3}\right.$ cells per well) were seeded in a 96-well blank plate and exposed to TP $(30,60,90,120 \mathrm{nM})$ for $12 \mathrm{~h}$. Another group was incubated for 3, 6, 12 and $24 \mathrm{~h}$ after TP (120 nM) was added. After that, the fluorescence was measured with the same experimental procedures as mentioned.

\section{Confocal fluorescence imaging of ${ }^{\cdot} \mathrm{OH}$ in living cells}

L-02 cells were seeded into $35 \mathrm{~mm}$ confocal dishes (Glass Bottom Dish) at a density of $1 \times 10^{4}$ per dish and incubated for $24 \mathrm{~h}$ at $37{ }^{\circ} \mathrm{C}$. The medium was then replaced with fresh serum-free culture medium containing APAP $(8 \mathrm{mM})$ for $4 \mathrm{~h}$ and then incubated with $1 \mathrm{nM}$ nanoprobe for different times at $37^{\circ} \mathrm{C}$. After that, the cells were washed three times with PBS. Confocal fluorescence imaging was performed to visualize the intracellular FAM fluorescence. FAM was excited at $488 \mathrm{~nm}$ with an argon ion laser, and the emission was collected from 505 to $535 \mathrm{~nm}$.

For APAP-induced cell injury imaging, cells were treated with APAP (1-8 $\mathrm{mM}$ ) for $4 \mathrm{~h}$ and then incubated with $1 \mathrm{nM}$ nanoprobe for $2 \mathrm{~h}$ before imaging. For the remediation investigation, cells were pretreated with NAC $(0.5,1,2 \mathrm{mM})$ or QUE $(5,10,20$ $\mu \mathrm{M})$ for $1 \mathrm{~h}$ before APAP $(8 \mathrm{mM})$ administration and then incubated with $1 \mathrm{nM}$ nanoprobe for $2 \mathrm{~h}$. After incubation, the cells were washed, and confocal fluorescence imaging was performed to visualize the intracellular FAM fluorescence.

For TP-induced cell injury imaging, cells were treated with TP $(30,60,90,120 \mathrm{nM})$ for $12 \mathrm{~h}$ and then incubated with $1 \mathrm{nM}$ nanoprobe for $2 \mathrm{~h}$ before imaging. For another group, cells were treated with TP (120 nM) for 3, 6, 9, 12 and $24 \mathrm{~h}$ and then incubated with $1 \mathrm{nM}$ nanoprobe for $2 \mathrm{~h}$ before imaging. After incubation, the cells were washed, and confocal fluorescence imaging was performed to visualize the intracellular FAM fluorescence.

\section{Statistical analysis}

Data were expressed as mean $\pm \mathrm{SD}$ from at least three experiments. One-way ANOVA was used to compare the treatment effects. $P<0.05$ was considered to be statistically significant.

\section{Conclusions}

In summary, we have reported an ${ }^{\circ} \mathrm{OH}$-responsive and hepatocytetargeted nanoprobe, which exhibits several advantages including high sensitivity, selectivity, stability and good biocompatibility. The nanoprobe with Gal modification can be effectively internalized into liver cells via an ASGPR-mediated endocytosis pathway. Confocal fluorescence imaging results confirm that the nanoprobe can be successfully utilized for visualizing intracellular ${ }^{\circ} \mathrm{OH}$ during the process of drug-induced liver cell injury. The positive time using the nanoprobe is superior to those of ALT- and AST-based conventional methods. Although the emission wavelength of the nanoprobe is located in the visible region, which limits the in vivo application of DILI imaging, this study should significantly broaden the perspectives for the further development of 
bioluminescent or near-infrared nanoprobes to predict DILI and to help prevent drug-induced side effects.

\section{Conflicts of interest}

The authors declare no competing financial interest.

\section{Acknowledgements}

This research was supported by the National Natural Science Foundation of China (21775166, 21505161), the Fundamental Research Funds for the Central Universities (2632017ZD10), the Natural Science Foundation of Jiangsu Province (BK20150701) and the Six Talent Peaks Project in Jiangsu Province.

\section{References}

1 S. Tujios and R. J. Fontana, Nat. Rev. Gastroenterol. Hepatol., 2011, 8, 202-211.

2 M. Chen, A. Suzuki, J. Borlak, R. J. Andrade and M. I. Lucena, J. Hepatol., 2015, 63, 503-514.

3 P. H. Hayashi, D. C. Rockey, R. J. Fontana, H. L. Tillmann, N. Kaplowitz, H. X. Barnhart, J. Gu, N. P. Chalasani, K. R. Reddy, A. H. Sherker, J. H. Hoofnagle and I. DrugInduced Liver Injury Network, Hepatology, 2017, 66, 1275-1285.

4 A. Srivastava, J. L. Maggs, D. J. Antoine, D. P. Williams, D. A. Smith and B. K. Park, Handb. Exp. Pharmacol., 2010, 7, 165-194.

5 J. S. Walsh and G. T. Miwa, Annu. Rev. Pharmacol. Toxicol., 2011, 51, 145-167.

6 M. Chen, V. Vijay, Q. Shi, Z. Liu, H. Fang and W. Tong, Drug Discovery Today, 2011, 16, 697-703.

7 A. Nasr, T. J. Lauterio and M. W. Davis, Adv. Ther., 2011, 28, 842-856.

8 W. R. Proctor, A. J. Foster, J. Vogt, C. Summers, B. Middleton, M. A. Pilling, D. Shienson, M. Kijanska, S. Strobel, J. M. Kelm, P. Morgan, S. Messner and D. Williams, Arch. Toxicol., 2017, 91, 2849-2863.

9 E. S. Bjornsson, O. M. Bergmann, H. K. Bjornsson, R. B. Kvaran and S. Olafsson, Gastroenterology, 2013, 144, 1419-1425.

10 R. P. van Swelm, C. Kramers, R. Masereeuw and F. G. Russel, Crit. Rev. Toxicol., 2014, 44, 823-841.

11 R. A. Nathwani, S. Pais, T. B. Reynolds and N. Kaplowitz, Hepatology, 2005, 41, 380-382.

12 M. J. Czaja, Semin. Liver Dis., 2007, 27, 378-389.

13 D. J. Antoine, D. P. Williams and B. K. Park, Expert Opin. Drug Metab. Toxicol., 2008, 4, 1415-1427.

14 S. Russmann, G. A. Kullak-Ublick and I. Grattagliano, Curr. Med. Chem., 2009, 16, 3041-3053.

15 D. Pessayre, A. Mansouri, A. Berson and B. Fromenty, Handb. Exp. Pharmacol., 2010, 11, 311-365.

16 A. J. Shuhendler, K. Pu, L. Cui, J. P. Uetrecht and J. Rao, Nat. Biotechnol., 2014, 32, 373-380.

17 H. E. Moser and P. B. Dervan, Science, 1987, 238, 645-650.

18 Y. Tang, F. Feng, F. He, S. Wang, Y. Li and D. Zhu, J. Am. Chem. Soc., 2006, 128, 14972-14976.
19 Q. Shen, Z. Nie, M. Guo, C. J. Zhong, B. Lin, W. Li and S. Yao, Chem. Commun., 2009, 929-931.

20 C. Liu, W. Chen, Z. Qing, J. Zheng, Y. Xiao, S. Yang, L. Wang, Y. Li and R. Yang, Anal. Chem., 2016, 88, 3998-4003.

21 B. Tang, N. Zhang, Z. Chen, K. Xu, L. Zhuo, L. An and G. Yang, Chemistry, 2008, 14, 522-528.

22 C. P. Liang, P. Q. Ma, H. Liu, X. Guo, B. C. Yin and B. C. Ye, Angew. Chem., Int. Ed., 2017, 56, 9077-9081.

23 Y. Sun, Q. Wang, J. Chen, L. Liu, L. Ding, M. Shen, J. Li, B. Han and Y. Duan, Theranostics, 2017, 7, 4424-4444.

24 X. Wu, Y. J. Tan, H. T. Toh, L. H. Nguyen, S. H. Kho, S. Y. Chew, H. S. Yoon and X. W. Liu, Chem. Sci., 2017, 8, 3980-3988.

25 A. A. D'Souza and P. V. Devarajan, J. Controlled Release, 2015, 203, 126-139.

26 N. Soh, K. Makihara, E. Sakoda and T. Imato, Chem. Commun., 2004, 496-497.

27 C. A. Mirkin, R. L. Letsinger, R. C. Mucic and J. J. Storhoff, Nature, 1996, 382, 607-609.

28 J. Li, B. Zhu, X. Yao, Y. Zhang, Z. Zhu, S. Tu, S. Jia, R. Liu, H. Kang and C. J. Yang, ACS Appl. Mater. Interfaces, 2014, 6, 16800-16807.

29 B. White, S. Banerjee, S. O'Brien, N. J. Turro and I. P. Herman, J. Phys. Chem. C, 2007, 111, 13684-13690.

30 W. Pan, T. Zhang, H. Yang, W. Diao, N. Li and B. Tang, Anal. Chem., 2013, 85, 10581-10588.

31 M. Zhuang, C. Ding, A. Zhu and Y. Tian, Anal. Chem., 2014, 86, 1829-1836.

32 J. He, X. Yang, B. Men and D. Wang, J. Environ. Sci., 2016, 39, 97-109.

33 W. Zhou, Y. Cao, D. Sui and C. Lu, Angew. Chem., Int. Ed., 2016, 55, 4236-4241.

34 A. Bertolini, A. Ferrari, A. Ottani, S. Guerzoni, R. Tacchi and S. Leone, CNS Drug Rev., 2006, 12, 250-275.

35 K. Du, A. Ramachandran and H. Jaeschke, Redox Biol., 2016, 10, 148-156.

36 J. A. Hinson, D. W. Roberts and L. P. James, Handb. Exp. Pharmacol., 2010, 196, 369-405.

37 C. C. Huang, W. Y. Pan, M. T. Tseng, K. J. Lin, Y. P. Yang, H. W. Tsai, S. M. Hwang, Y. Chang, H. J. Wei and H. W. Sung, Biomaterials, 2016, 74, 53-63.

38 R. Zhang, J. Zhao, G. Han, Z. Liu, C. Liu, C. Zhang, B. Liu, C. Jiang, R. Liu, T. Zhao, M. Y. Han and Z. Zhang, J. Am. Chem. Soc., 2016, 138, 3769-3778.

39 A. W. Boots, G. R. Haenen and A. Bast, Eur. J. Pharmacol., 2008, 585, 325-337.

40 P. E. Lipsky and X. L. Tao, Semin. Arthritis Rheum., 1997, 26, 713-723.

41 X. J. Li, Z. Z. Jiang and L. Y. Zhang, J. Ethnopharmacol., 2014, 155, 67-79.

42 Y. Ma, Z. Wang, M. Zhang, Z. Han, D. Chen, Q. Zhu, W. Gao, Z. Qian and Y. Gu, Angew. Chem., Int. Ed., 2016, 55, 33043308.

43 S. Wang, W. Lu, O. Tovmachenko, U. S. Rai, H. Yu and P. C. Ray, Chem. Phys. Lett., 2008, 463, 145-149.

44 F. Liu, T. Bing, D. Shangguan, M. Zhao and N. Shao, Anal. Chem., 2016, 88, 10631-10638. 